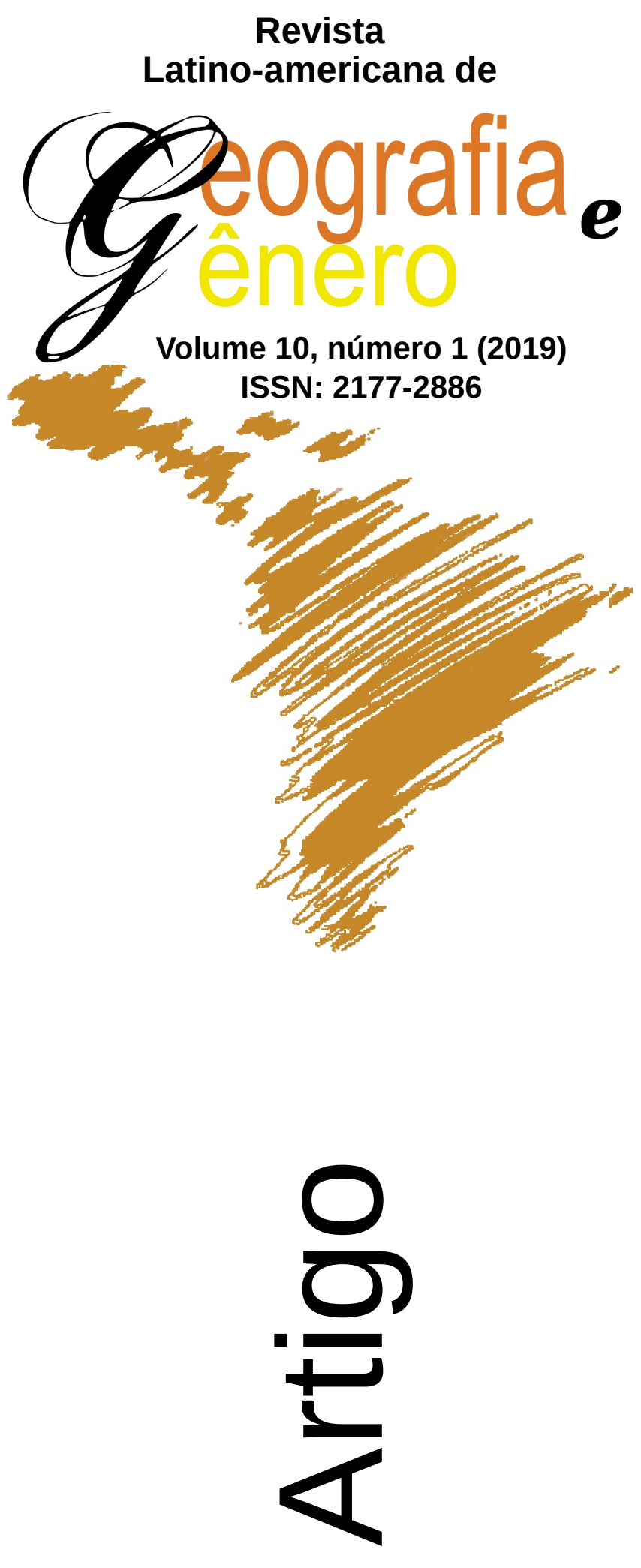

\title{
Inserção no Mercado de Trabalho Brasileiro por Haitianos: Uma Perspectiva de Gênero
}

Inserción en el Mercado de Trabajo Brasileño por Haitiano: Una Perspectiva de Género

Haitians Insertion in the Brazilian Job Market: A Gender Perspective

\author{
Carolina Ribeiro \\ Pontifícia Universidade Católica de Minas \\ Gerais - Brasil \\ carroile@yahoo.com.br \\ Duval Fernandes \\ Pontifícia Universidade Católica de Minas \\ Gerais - Brasil \\ duval@pucminas.br

\section{Carolina Mota-Santos} \\ Pontifícia Universidade Católica de Minas \\ Gerais - Brasil \\ cmmotasantos@gmail.com
}

Como citar este artigo:

RIBEIRO, Carolina; FERNANDES, Duval; MOTASANTOS, Carolina. Inserção no Mercado de Trabalho Brasileiro por Haitianos: Uma Perspectiva de Gênero. Revista Latino Americana de Geografia e Gênero, v. 10, n. 1, p. 126-145, 2019. ISSN 2177-2886.

Disponível em:

http://www.revistas2.uepg.br/index.php/rlagg 


\title{
Inserção no Mercado de Trabalho Brasileiro por Haitianos: Uma Perspectiva de Gênero
}

\author{
Inserción en el Mercado de Trabajo Brasileño por Haitiano: Una Perspectiva \\ de Género
}

Haitians Insertion in the Brazilian Job Market: A Gender Perspective

\begin{abstract}
Resumo
O objetivo deste trabalho é analisar a partir de uma perspectiva de gênero como se deu o processo de inserção de haitianos no mercado de trabalho brasileiro, que migraram para o Brasil após o terremoto de 2010. O referencial teórico retrata as origens e as causas dos movimentos migratórios para em seguida discutir o processo de migração, trabalho e gênero. Os resultados indicaram que as mulheres quando chegam ao Brasil têm como principal atividade os serviços gerais. A maioria dos homens se submetem a serviços braçais em péssimas condições de trabalho, e a situação das mulheres é ainda mais delicada, uma vez que enfrentam grandes dificuldades de encontrar trabalho que seja flexível para levar e buscar os filhos na creche.
\end{abstract}

Palavras-Chave: Imigração; Gênero; Trabalho; Mercado de Trabalho.

\section{Resumen}

El objetivo de este trabajo es analizar a partir de una perspectiva de género como se dio el proceso de inserción de haitianos en el mercado de trabajo brasileño, que migran hacia Brasil después del terremoto del 2010. La referencia teórica retrata los orígenes y las causas de los movimientos migratorios para en seguida discutir el proceso migratorio, trabajo y género. Los resultados indicaron que las mujeres cuando llegan a Brasil tienen como principal actividad los servicios generales. La mayoría de los hombres se someten a trabajos de fuerza en pésimas condiciones de trabajo, y la situación de la mujeres es aún más delicada, una vez que enfrentan grandes dificultades de encontrar trabajo que sea flexible para llevar y buscar a sus hijos al jardín.

Palabras-Clave: Inmigración; Género; Trabajo; Mercado de Trabajo.

\begin{abstract}
The objective of this paper is to analyze from a gender perspective how the process of insertion of Haitians that migrated to Brazil after the earthquake of 2010 occurred in the Brazilian job market. The theoretical background portrays the origins and causes of the migration movements and then discusses the process of migration, work and gender. The results indicated that the main positions occupied by women when they arrive in Brazil are in general services. Most men only manage to get manual jobs in awful working conditionss and the women's situation is even more delicate as they face great difficulties in finding work that is flexible to take and pick up children in day care.
\end{abstract}

Keywords: Immigration; Gender; Labor; Job Market.

Carolina Ribeiro, Duval Fernandes, Carolina Mota-Santos

Revista Latino-americana de Geografia e Gênero, Ponta Grossa, v. 10, n. 1, p. 126 - 145, jan. / jun. 2019. 


\section{Introdução}

O fenômeno da migração suscita processos emergentes de subjetivação na contemporaneidade e necessita ser mais estudado, em suas articulações com relações de gênero, com o sentido do trabalho e tantas outras articulações (COSTA; JUSTO, 2016). Há um vasto campo para ser explorado pela geografia brasileira em relação aos estudos sobre temáticas relacionadas às mulheres, gênero e sexualidade (CESAR; PINTO, 2015).

Produções da subjetividade são transformadas por processos migratórios oferecendo modificações nas relações de trabalho, nas relações familiares e de identificações culturais (COSTA; JUSTO, 2016). É nesse contexto que o objetivo deste trabalho se insere: analisar a partir de uma perspectiva de gênero como se deu o processo de inserção de haitianos no mercado de trabalho brasileiro, que migraram para o Brasil após o terremoto de 2010.

Entender o processo da migração, sua intensidade e distribuição são elementos essenciais para contribuir na criação de políticas que auxiliem no processo de sua fixação e adaptação no país. No caso específico da imigração no Brasil, Fernandes et al. (2013) ressaltam que não se pode dizer com certeza qual foi o motivo específico que provocou a migração haitiana para o Brasil, mas é certo que, a partir de 2010, após o terremoto, esse fluxo se ampliou por diversas razões e dentre elas estão as restrições impostas à imigração pelos EUA e França, até então principais escolhas dos fluxos migratórios dos haitianos.

O movimento migratório Haiti - Brasil começa a ser percebido no final de 2010, quando se estimava que algumas centenas de haitianos haviam entrado no Brasil através das cidades fronteiriças: Tabatinga (AM), Brasiléia e Assis Brasil (AC), localizadas no Norte do país. Em 2011, a ampliação do número de solicitações de refúgio de haitianos apresentadas ao Comitê Nacional para os Refugiados (CONARE) fez com que a situação demandasse alguma atitude por parte do governo brasileiro. Os procedimentos adotados seguiam os seguintes caminhos: ao ter a demanda de refúgio recusada pelo CONARE, o processo do imigrante haitiano era encaminhado ao CNIg, procedimento este respaldado na Resolução Recomendada (RR) 08/2006. O conselho por sua vez concedia aos imigrantes haitianos autorização para permanência no território brasileiro por razões humanitárias, sendo essa autorização amparada pela Resolução Normativa (RN) 27/2008.

Esses procedimentos tomados pelo governo brasileiro não foram suficientes para atender o crescente volume de imigrantes haitianos que chegavam ao país. A maioria, em situação irregular, entrava pelas cidades fronteiriças após percorrer caminhos obscuros e perigosos, chegando ao Brasil com situação extrema de vulnerabilidade, sem dinheiro e sem saber falar o idioma português (RIBEIRO, 2015). Logo, desde o início do fluxo migratório, a concessão de vistos ocorria via pedido de refúgio quando o imigrante haitiano já estava em território brasileiro. Mas a partir de 2012, através da RN 97/2012, que por sinal é uma resolução específica para haitianos, os vistos para o Brasil passaram a ser concedidos também no Haiti.

A reflexão relacionada à questão de gênero proposta neste trabalho encontra-se na busca por identidades nos fenômenos migratórios, contribuindo 
para o destaque dos papéis dos homens e mulheres nesse processo, desconstruindo a visão da mulher como coadjuvante. Além disso, é importante que se trate a questão de gênero não apenas como uma temática feminina.

Retirar a migrante mulher da invisibilidade não anula o importante papel que o migrante homem possui no processo migratório. Ambos os sexos têm participação efetiva e muitas vezes complementar nesse processo. Cabe então analisar tais diferenças e ressaltar possíveis elementos que fazem parte das complexidades existentes nos projetos migratórios masculinos e femininos.

Para Peres (2016), quando se incorpora aos estudos dos fluxos migratórios, os diferencias por sexo, considerando as relações de gênero e aprofundando além da descrição homem e mulher, as teorias migratórias acabam por avançar, pois passa-se a compreender esferas muito específicas da mulher migrante, como família e trabalho. A autora afirma que as transformações experimentadas pelo homem e pela mulher no processo migratório são diferentes e impactam de maneira diferenciada suas realidades familiar e domiciliar.

\section{Origem e Causas dos Movimentos Migratórios}

São muitos os autores que trabalham a migração internacional com diversas abordagens. Dentre eles pode-se destacar Ravenstein (1885), que criou as leis da migração a partir de análises das disparidades econômicas entre os condados do Reino Unido no século XIX; Lee (1966), que aborda os efeitos de atração e repulsão no fenômeno migratório e Piore (1979), que aborda o problema aplicando a teoria de Mercado Dual.

Além desses autores, há aqueles que seguiram à teoria neoclássica. Essa teoria se divide em duas correntes de análise: a macroteórica, que tem como principais expoentes Lewis (1963) e a microteórica, com Borjas (1989) como seus representantes. Essas teorias admitem que a migração internacional se origina da diferença nas taxas salariais entre países e propõem que mercados de trabalho em desequilíbrio podem ter na migração um fator equilibrante (NUNAN, 2006).

A análise sobre as causas e origens dos movimentos migratórios se inicia com o geógrafo Ravenstein (1885), considerado pioneiro no processo de estudos de caso sobre migração. As facilidades oferecidas pelo meio de transporte, o desenvolvimento da marinha mercante, o hábito de viajar, a educação dos trabalhadores, além de facilidades educacionais, salubridade do clima e/ou falta de bens essenciais à sobrevivência são facilitadores migratórios.

Ravenstein (1885) observa diferenças entre a migração de homens e mulheres levantando um pouco a discussão de migração e gênero em suas análises. Quanto à migração feminina, as estatísticas analisadas da época indicavam que as mulheres migrariam mais que os homens e que elas não se deslocavam apenas para o serviço doméstico como muitos poderiam pensar, mas a busca pelo trabalho manufatureiro também era significativa.

Os locais onde a mão de obra masculina era mais procurada, eram os centros de atividades de mineração de carvão e ferro, indústria mecânica e outras atividades consideradas como masculinizadas. Sendo assim, já se 
observava certo diferencial no processo migratório entre homens e mulheres no que tange o acesso ao mercado de trabalho (RAVENSTEIN, 1885). Para o autor, o que move as migrações é a procura pelo trabalho.

$\mathrm{O}$ fenômeno migratório da atualidade é bem mais complexo que o de antigamente, não se restringindo apenas aos interesses econômicos, políticos ou ambientais, mas também à 'rede' de contatos que existe entre as várias relações humanas inseridas nesses contextos, inclusive as relações de gênero. Os deslocamentos humanos devem ser devidamente relativizados e compreendidos em seus contextos apropriados. Consideram-se as redes sociais como estruturas sociais constituídas de diferentes mecanismos (posições e papéis, homem e mulher, dominador e dominado, formais e concretos, etc.) (RIBEIRO, 2015).

Liu (2011) também levanta a questão do gênero e afirma que ele influencia na tomada de decisão na hora de migrar desde o momento em que é concebida. O sexo, a família e a comunidade de onde o migrante surge são elementos influenciadores na atitude de migrar. Existe diferença nas relações entre laços fortes e fracos na procura por emprego.

Se uma pessoa migra, maior será a influência que ela exerce diretamente na probabilidade de outras pessoas do seu ciclo social migrarem também. De acordo com a autora, uma pessoa que migra e que mantém laços com outra pessoa que já migrou, acaba por contribuir ou acarretar na diminuição dos custos da migração e ainda aumenta benefícios e facilidades no processo migratório (LIU, 2011).

Apesar de Ravenstein (1885) incluir a questão do gênero em suas leis e perceber que há diferenciação entre os destinos de homens e mulheres de acordo com os tipos de trabalho ofertados, alguns estudos e mesmo manifestações da mídia não tomam o cuidado de considerar a questão de gênero, apesar de ela estar sempre intrínseca ao processo migratório.

As mulheres continuam sendo invisíveis ou agrupadas nas mesmas dimensões que os homens quando se fala em processo migratório, mesmo com o crescimento dos dados. As atribuições diferenciadas das causas para a migração, muitas vezes estão relacionadas, no caso da mulher, à motivações do campo afetivo e familiar. Além disso, falam de alguém que vem depois, tendo a estrada já aberta por homens. Quando o contrário acontece, os motivos não são bem visíveis e/ou racionalmente explicáveis. (TEDESCO, 2011). Sendo assim, é preciso trazer à tona a equidade existente entre homens e mulheres no processo migratório (PERES, 2016), de forma que as mulheres saiam do papel secundário no qual não fazem parte, mas em muitos casos são colocadas nessa posição.

Os fluxos migratórios podem seguir determinados padrões que dependem de vários fatores, como contexto social e econômico. Estes podem estar diretamente ou não interligados as questões de gênero, seja no tocante de quem é, ou passa a ser o provedor da família, a responsabilidade para com os filhos, o almejo pela reunião familiar, chegando até mesmo ao tipo de trabalho que o migrante ocupava antes e depois de migrar. Todos esses elementos sofrem forte influência cultural e política. Política no sentido de transformá-los como seres iguais perante as leis, nivelando-os de maneira generalizada, quando isso não deveria acontecer, e, em uma perspectiva cultural exatamente por submeter o 
migrante a determinadas situações consideradas específicas para homens (trabalho braçal, provedor, macho) e mulheres (trabalho doméstico, cuidadora dos filhos, delicada) (RIBEIRO, 2015).

As normas sociais definem os espaços que devem ser ocupados de acordo com as classes e gêneros e, sendo assim, as normas estabelecidas tanto para mulheres quanto homens influenciam as formas e ritmos experimentados nas migrações de homens e mulheres (RIBEIRO, 2015). É sobre essas normas relacionadas ao processo migratório, trabalho e gênero que vamos aprofundar a seguir.

\section{Trabalho, Gênero e Migração}

As desvantagens da mulher no mercado de trabalho são um reflexo de um patriarcado e do papel de subordinação atribuído às mulheres na sociedade (LOURO, 2013; CAPPELLE et al, 2007). Alguns estudos sobre migração apontam que, geralmente, as mulheres apresentam taxas de atividades econômicas mais elevadas no local de destino do que em seu país de origem.

Em um mercado de trabalho canadense, por exemplo, em diferentes setores, as mulheres enfrentavam dificuldades especiais para encontrar "emprego de sobrevivência". Entretanto, em longo prazo, o maior investimento das mulheres em educação pós-secundária adicional no Canadá as colocou em uma posição um pouco melhor do que os homens (CREESE e WIEBE, 2009). Outro exemplo é a migração haitiana para a República Dominicana. De acordo com Becerra et al, (2011), os homens atuam majoritariamente em atividades do ramo da construção civil, enquanto as mulheres atuam em atividades comerciais e domésticas geralmente com caráter não formal.

A presença de mulheres estrangeiras em trabalhos domésticos favorece a progressiva entrada das mulheres autóctones no mercado de trabalho, intensifica no interior das famílias as profundas mudanças culturais no interior das identidades de gênero no âmbito familiar/afetivo, colaboram para efetivar, no interior da sociedade hospedeira (e para eles), a refutação da chamada "ideologia da domesticidade”. (TEDESCO, 2011, p.6).

As teorias de migração avançam ao tentarem entender a vida da mulher imigrante no que se refere ao trabalho e a família e o que se percebe é que "homens e mulheres reconstroem, negociam e reafirmam relações de poder, hierarquia e a própria identidade" (PERES, 2015, p.1). De acordo com Costa e Justo (2016), não se deve aplicar à imigração a relação reducionista de busca por melhor condição de vida, pois a busca é por novas formas de construção de si mesmo. Falar de migração é, portanto, falar de reconstrução da identidade (PERES, 2015), de "buscar novas formas de se relacionar com o mundo" (COSTA; JUSTO, 2016, p.37).

Para Itzigsohn e Giorguli-Saucedo (2005), as experiências de homens e mulheres imigrantes apresentam desafios semelhantes, mas também são afetados de forma diferente pelos fatores mais relevantes no processo de incorporação e participação transnacional. 
Por isso não se pode dizer que o papel da mulher na imigração é sempre o de coadjuvante. Muitas vezes, elas assumem o papel principal como foi o caso das mulheres que ajudaram os maridos na colonização de Rondônia. Elas tiveram participação especial em muitos fatos, mas sempre foram deixadas nos bastidores (SILVA et al, 2015). Na verdade, Zentgraf (2002) ressalta que a percepção das experiências das mulheres imigrantes é bastante diversa e complexa. Enquanto algumas acreditam que o emprego remunerado fora do lar não é uma experiência nova e a divisão de trabalho do gênero doméstico não mudou significativamente após a migração, para outras mulheres havia um sentimento de empoderamento, liberdade e autoconfiança enquanto negociavam papéis tradicionais de gênero em um novo contexto social e cultural.

Além disso, quando se discute sobre a mulher no processo migratório é para enquadrá-la em dimensões ligadas à prostituição, a facilidade de exploração do seu trabalho e/ou a fuga do local de origem relacionada a problemas familiares (TEDESCO, 2011). Dimensões estas muitas vezes aceitas com normalidade, como a naturalização social do que é ser homem e do que é ser mulher na sociedade. A incidência de violência doméstica, por exemplo, não é maior do que a da população nativa. As experiências de mulheres imigrantes em situações de violência doméstica são muitas vezes exacerbadas por sua posição específica como imigrantes, isso ocorre devido a dificuldades com a linguagem, o isolamento, a falta de contato com a família e a comunidade, a falta de acesso a empregos dignos, status legal incerto, entre outros (MENJÍVAR; SALCIDO, 2002).

Bourdieu (2000) declara que as divisões entre os sexos se apresentam como algo natural, normal e até mesmo inevitável. O comportamento do ser humano atrelado ao gênero aparece nos grupos sociais como algo imposto e predeterminado, como se as atitudes fossem direcionadas àquilo que é permitido ou não aos homens e às mulheres.

$\mathrm{Na}$ divisão das atividades sexuais, há um acordo de oposições entre o macho e a fêmea que recebe sua necessidade objetiva ou subjetiva, ou seja, um sistema de oposições homólogas: "[..] alto e baixo, para cima e para baixo, frente e atrás, esquerda e direita, em linha reta e curva [...]" (BOURDIEU, 2000, p.20).

A sociedade possui uma visão 'androcêntrica', em que não há necessidade de discurso legitimado por parte do homem. A ocupação dos espaços já é predeterminada, guardando-se os espaços de interação para os homens e os reservados para as mulheres. As diferenças corporais existentes entre homens e mulheres se tornam elementos de afirmação das diferenças sociais que existem entre os mesmos (BOURDIEU, 2000).

Pode-se dizer o mesmo quando se discute: processos migratórios versus gênero. Tedesco (2011) ressalta que as estatísticas confirmam que a presença intensa da mulher nos processos migratórios é uma das características da imigração internacional. Realidade que não deve ser explicada apenas pelo fato da legislação de alguns países permitirem o reagrupamento familiar. Apesar disso, na maioria dos casos, elas continuam invisíveis ou agrupadas em uma situação de dependência dos homens.

Apesar de o movimento feminista ter possibilitado uma mudança nas 
relações de gênero, na medida em que homens e mulheres puderam construir novas formas de ser no mundo: de agir, de se comportar, de se relacionar, ou seja, se libertaram dos antigos estereótipos, tais como, sensibilidade para as mulheres e agressividade para os homens (ARAÚJO, 2005) a mulher no processo migratório ainda se encontra de forma invisível e/ou dependente, ou seja, reforçando os estereótipos. Suárez-Orozco e Qin (2006) ressaltam a necessidade de pesquisas que incluem a necessidade de considerar como, quando e por que faz a diferença para ser imigrante, ser de um país específico ou ser feminino e não masculino.

Bourdieu (2000) considera que a dominação masculina tem todas as condições para seu pleno exercício. Há uma preeminência, que é reconhecida de maneira universal pelos homens, que se afirma dentro das estruturas sociais e que concede privilégios aos mesmos. A reprodução androcêntrica na sociedade é praticada por um consenso que vem até mesmo das mulheres, pois essas muitas vezes se submetem ao domínio masculino acreditando que isso é algo natural. É o homem quem ocupa os espaços públicos como a praça, o clube, o mercado e os bares, e à mulher são destinados os espaços privados, geralmente domésticos.

Essas divisões se refletem diretamente nas questões de trabalho. Os homens historicamente costumam ocupar os postos de trabalho em que há maior interação, maior nível de negociação e exercício de força física, ou cargos de chefia onde se confirma a ideia subentendida de dominação masculina. Já a mulher se destina a trabalhos domésticos ou no campo da educação (BOURDIEU, 2000).

No caso de estudos na Geografia é possível encontrar também uma preocupação com as questões de gênero. Silva (2009) aponta que, durante muito tempo, as existências de determinados grupos sociais como, mulheres, não brancos, homossexuais, entre outros, foram marginalizadas e/ou ignoradas pelos estudos científicos, o que, de certa maneira, deu legitimação aos discursos hegemônicos considerados pela autora como um discurso da "geografia branca, masculina e heterossexual" (SILVA, 2009, p. 26), impedindo o questionamento das diversidades e pluralidades.

Foi no século XXI que começou o crescimento de produção intelectual da geografia brasileira de trabalhos científicos com base em categorias sociais, tais como, gênero, sexualidade e mulheres. Entretanto, ainda assim verificamse locais que se concentram em torno de tradições epistemológicas que tendem a resistência em aprofundar em novas vertentes, tais como, a feminista e a Queer (CESAR; PINTO, 2015).

\section{Metodologia}

As informações sobre os haitianos contidas neste trabalho se basearam a partir de um levantamento exploratório e investigativo de informações qualitativas e quantitativas por meio de questionários e entrevistas de grupos focais retiradas da pesquisa "Migração haitiana para o Brasil: diálogo Bilateral", realizada pela Organização Internacional para as Migrações (OIM) em projeto apoiado pelo Conselho Nacional de Imigração (CNIg) do Ministério de Trabalho e Emprego. Essa pesquisa foi realizada pelo Grupo de 
Estudos Distribuição Espacial da População (GEDEP), que pertence ao Programa de Pós Graduação em Geografia da Pontifícia Universidade Católica de Minas Gerais, (PUC-Minas).

Ouviu-se 340 imigrantes haitianos por meio da aplicação de questionários e nove grupos focais foram realizados (quatro com homens e cinco com mulheres).

Os questionários foram aplicados em Porto Velho (RO), Belo Horizonte (MG), Curitiba (PR) e São Paulo (SP). Em Brasília e Campinas houve só a aplicação de questionário, e, em Manaus, a realização de um grupo focal com mulheres. Já os Grupos Focais, de homens e mulheres em separado, foram realizados em Belo Horizonte (MG), Curitiba (PR), Porto Velho (RO) e São Paulo (SP).

As mulheres foram entrevistadas separadamente dos homens, tendo a liberdade de se expressarem. Tanto os questionários quanto as discussões propostas nos grupos focais tinham o intuito de levantar informações sobre o processo migratório do migrante haitiano ao se dirigir para o Brasil e também sua fixação e adaptação ao Brasil.

Os dados dos questionários foram tabulados e organizados no laboratório do GEDEP, contendo informações em relação a idade, sexo, trabalho, família, motivos que fizeram deixar o Haiti, meios e tempo de transição até chegar ao Brasil, escolaridade, saúde, trabalho e reflexão subjetiva do processo migratório Haiti - Brasil. As informações foram conferidas uma a uma e cruzadas entre si através do software SPSS, evitando que houvesse contradições entre as informações. Após a conferência, os dados se tornaram disponíveis para que outras pesquisas fossem realizadas com os mais variados recortes.

Os grupos focais foram realizados na língua créole (BENTOLILA, 1981; CAISSE, 2012) e, na medida do possível, coordenados por haitianos. As gravações foram traduzidas e digitalizadas pelos coordenadores dos grupos e, no caso de Belo Horizonte, por haitianos que seguiam os cursos de português oferecidos pelo Centro Zanmi.

No caso específico deste artigo optou-se por fazer um recorte e cruzamento dos dados com o intuito de obter informações a respeito do trabalho e gênero no processo migratório.

\section{Apresentação e Discussão dos Resultados}

Dos 340 entrevistados, 19\% (65) eram mulheres, enquanto 81\% (275) eram homens. Temos então os homens como maioria dos haitianos entrevistados, conforme tabela 1 a seguir. Apesar do número menor de mulheres entrevistadas, as respostas são de relevância, por expressarem o pensamento da mulher migrante haitiana no Brasil, mesmo sendo em menor quantidade do que os relatos dos homens. Para a análise os dados serão comparados em termos percentuais.

As respostas das mulheres migrantes são importantes não apenas por terem sido consideradas invisíveis ao longo de décadas, mas também para desconstruir a visão de que a mulher é coadjuvante no processo migratório. Além disso, conforme discutido na literatura, incorporar as diferenças entre os 
Inserção no Mercado de Trabalho Brasileiro por Haitianos: Uma Perspectiva

de Gênero

gêneros acaba por avançar os estudos sobre os fluxos migratórios, uma vez que as transformações vivenciadas por mulheres e homens são diferentes.

Tabela 1 - Número de haitianos entrevistados por sexo - 2013

\begin{tabular}{|l|c|c|}
\hline \multicolumn{1}{|c|}{ Sexo } & Frequência & Percentual \\
\hline Masculino & 275 & 80,9 \\
\hline Feminino & 65 & 19,1 \\
\hline Total & 340 & 100,0 \\
\hline
\end{tabular}

A pirâmide etária dos entrevistados respeitou os intervalos quinquenais de idade. Para 13 entrevistados: 10 homens $(3,6 \%)$ e 03 mulheres $(4,6 \%)$ não havia informação sobre a idade no momento da entrevista.

Gráfico 1 - Idade e sexo dos entrevistados

Haitianos entrevistados - Distribuição por idade e sexo - 2013

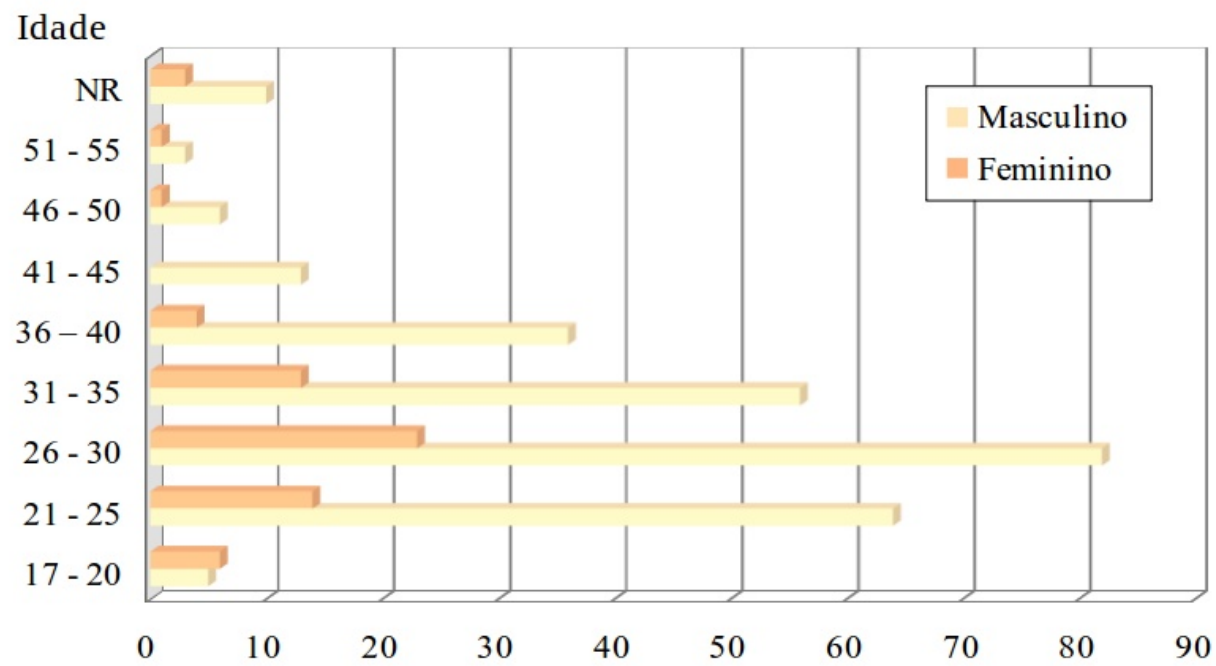

Fonte: Pesquisa OIM/CNIg (2013) - Autora: RIBEIRO (2015)

Analisando separadamente homens e mulheres, percebe-se que o número mais significativo de imigrantes homens se encontra na faixa de 25 a 29 anos em primeiro lugar e, 30 a 34 anos em segundo lugar. O mesmo ocorre também com as mulheres entrevistadas. A idade média dos homens entrevistados é de 30 anos, e das mulheres é de 28 anos.

Em relação à educação, as mulheres entendem que para se conseguir um emprego é necessário que se tenha formação profissional e elas apresentam o desejo de estudar. Algumas delas já migraram para o Brasil com algum tipo de formação, seja ela técnica ou superior. Elas afirmam que aproveitam os cursos oferecidos tanto de língua portuguesa como de formação profissional, porém o contato com os estudos aqui no Brasil ainda é pequeno entre os entrevistados, uma vez que há dificuldade (1) no reconhecimento de diplomas e certificados, (2) no conhecimento do idioma para entrar na escola, (3) no horário das aulas incompatíveis com a atividade desenvolvida. Os principais cursos escolhidos pela maioria masculina e feminina é o de língua portuguesa, um dos maiores desafios que eles declaram enfrentar ao chegar no Brasil. 
Inserção no Mercado de Trabalho Brasileiro por Haitianos: Uma Perspectiva

de Gênero

Gráfico 2 - Nível de escolaridade

Nível de escolaridade dos haitianos entrevistados - 2013

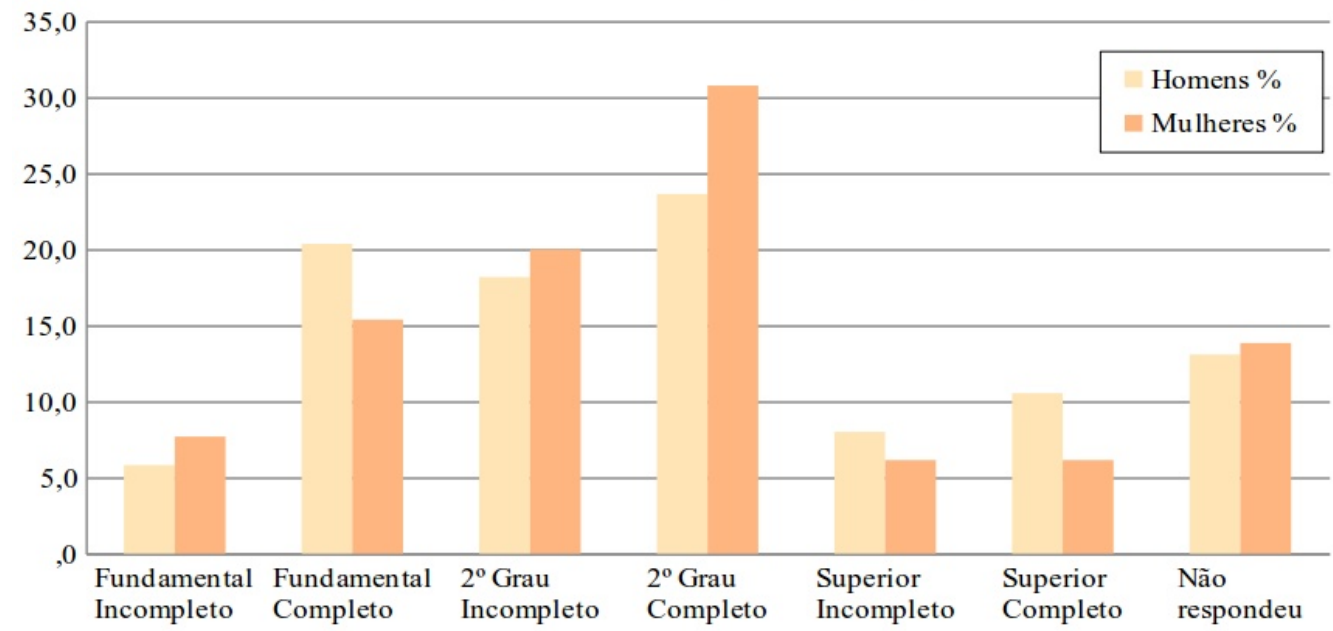

Fonte: Pesquisa OIM/CNIg (2013) - Autora: RIBEIRO (2015)

De acordo com o gráfico acima, tanto os homens quanto as mulheres possuem, em sua maioria o segundo grau completo. (30\%) de mulheres e (24\%) de homens. Já em relação ao curso superior (completo e incompleto), os homens apresentam uma porcentagem maior $(18 \%)$ em relação às mulheres $(12 \%)$.

De acordo com os entrevistados, tantos os homens quanto as mulheres haitianas têm como principal motivo de terem deixado o Haiti a busca por trabalho, estudo, melhores condições de vida e condições para ajudar a família.

Gráfico 3 - Motivos que levaram a deixarem o Haiti

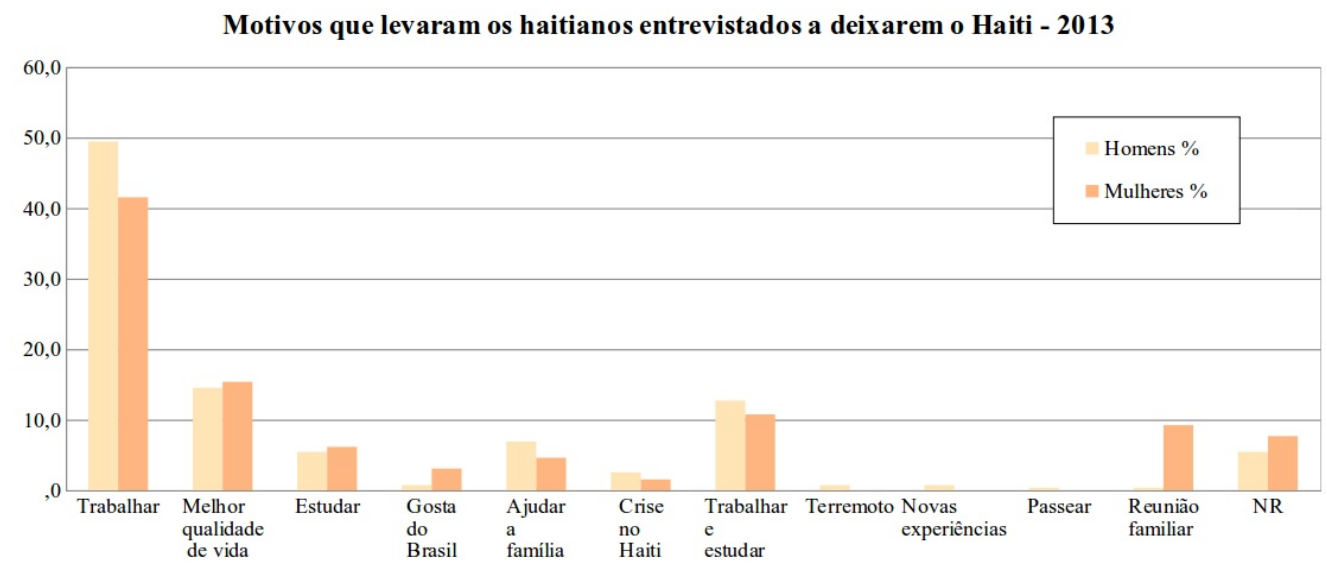

Fonte: Pesquisa OIM/CNIg (2013) - Autoria: RIBEIRO, (2015)

O gráfico acima mostra que as mulheres haitianas também apresentam o motivo de reunião familiar, ou seja, vem para o Brasil para encontrar os maridos que já estão aqui. Entretanto, essa não é a única razão para se realizar a migração. Conforme discutido no referencial teórico deste trabalho, alguns estudos e manifestações da mídia não consideram a questão de gênero e 
agrupam as mulheres nas mesmas dimensões que os homens. Existe a necessidade de se realizar a migração por motivo de reunião familiar, mas este não é o único motivo.

A literatura ressalta que as causas estão muitas vezes relacionadas ao campo afetivo familiar. No caso desta pesquisa, a partir do gráfico 3 acima percebe-se que os motivos mais relatados pelas migrantes mulheres são relacionados ao trabalho e por melhor qualidade de vida.

O motivo mais evidente é a necessidade de trabalhar, tanto para homens quanto para mulheres, entretanto, tanto homens como mulheres passam por situações e constrangimentos, pois há uma série de informações que não chegam ao conhecimento deles antes de migrar. Logo, em algumas situações específicas que serão retratadas a seguir não houve diferença em relação ao gênero.

A questão salarial é uma ilusão, os descontos de ordem previdenciária e laboral que incidem sobre os salários têm seus reflexos nos contracheques, por exemplo, e é algo que os migrantes haitianos possuem muita dificuldade de entendimento.

A rotatividade nos trabalhos é relativamente alta, visto que quase a metade dos entrevistados, homens e mulheres, já mudaram de emprego desde que chegaram ao Brasil, ou seja, tiveram mais de um emprego no período de 3 anos (2010 - 2013). A tabela 3 ilustra essa situação dos entrevistados.

Em outras situações, por exemplo, quando se fala em desrespeito, isso aparece muito mais nas falas dos homens.

Tabela 2 - Quantas vezes já mudaram de emprego desde que chegaram ao Brasil- 2013

\begin{tabular}{|l|c|c|}
\hline & Homens \% & Mulheres \% \\
\hline Uma & 12 & 9 \\
\hline Duas & 17 & 5 \\
\hline Três & 6 & 8 \\
\hline Quatro & 2 & 0 \\
\hline Cinco & 1 & 2 \\
\hline Não se aplica ${ }^{1}$ & 46 & 54 \\
\hline Não respondeu & 16 & 22 \\
\hline
\end{tabular}

Pode-se perceber que os motivos que levam os homens a mudarem são salariais. Nas entrevistas eles afirmam, em muitos casos, terem abandonado o trabalho por vontade própria ou em busca de outros serviços com melhores remunerações.

O desrespeito no tratamento entre patrão e empregado, ou até mesmo com colegas de trabalho são queixas relatadas pelos imigrantes haitianos homens.

1 Esse caso se refere aos entrevistados que não chegaram a arrumar nenhum trabalho no Brasil ou que nunca mudaram de emprego. 
Inserção no Mercado de Trabalho Brasileiro por Haitianos: Uma Perspectiva

de Gênero

Trabalhei durante um mês, ele me descontou a comida [rindo], o dinheiro de casa, ele me deu 119 Reais. Quando tomei o envelope e abri, eu percebi que eram 119 Reais. Tomei, dobrei e falei para ele: como você começou a tomar, toma tudo. Como? Eu paguei uma passagem 1500 U\$ para chegar até aqui e passei por muitas coisas ruins. Mas não é por 119 Reais que vou caminhar de cabeça baixa diante de ti. (Migrante Haitiano - Esmeraldas / MG).

$\mathrm{O}$ entrevistado contou que deixou esse trabalho e encontrou outro como canalizador. Além disso, ele relatou que mesmo nesse outro trabalho passou por situações difíceis.

O primeiro dia, o patrão me deu um plano / uma planta, as peças e disse: você é mestre, se você é mestre toma a planta. Eu observei como eles trabalham. Um trabalho que deveria ser feito em 3 dias, para mostrar a eles que não estou falando mentiras, fiz um banheiro completo para ele num dia só. No dia seguinte, quando ele voltou me perguntou por que estava parado? Respondi: não, foi só um banheiro que tinha que fazer, já acabou. Ele tirou sua trena, mediu todo, e tudo foi normal. (Migrante Haitiano - Esmeraldas / MG).

O desrespeito para alguns entrevistados está relacionado ao valor recebido pelos trabalhos realizados.

Fui estudar algo. Semana passada fui fazer a formação no "SENAC2", um curso de hotelaria. Como "GARÇOM". Fico observando para ver, se é verdade que eles querem nos levar como Haitianos, como escravos ou se é respeito que eles não têm pelos diplomas que vêm do Haiti. Tudo bem parece que eles não têm consideração pelos diplomas do Haiti. Mas, se no meu serviço, consigo fazer as coisas, você deve me respeitar. O problema do trabalho para muitas pessoas, para os Haitianos, é sempre assim. Nós trabalhamos para eles e eles não nos pagam nada. Tem também aqueles que estão fazendo muito dinheiro conosco. (Migrante Haitiano - Esmeraldas / $M G$ ).

Já varias pessoas me enganam no momento do pagamento, na construção civil, mas agora estou buscando onde eu posso trabalhar com tranquilidade. (Migrante Haitiano - Curitiba/PR).

Já com as mulheres a situação é diferente. Por terem muita dificuldade de se comunicarem devido à língua, elas são dispensadas de seus trabalhos. Os trabalhos femininos, quando braçais (faxineira. babá, garçonete), exigem o mínimo de comunicação com algum brasileiro.

Eu tinha um emprego, mandaram embora, por causa da língua. Cada uma de nós mulheres tem filhos esperando por nós. (Migrante Haitiana - Porto Velho / RO).

2 Instituição educacional para formação profissional.

Carolina Ribeiro, Duval Fernandes, Carolina Mota-Santos 
Inserção no Mercado de Trabalho Brasileiro por Haitianos: Uma Perspectiva

de Gênero

O primeiro trabalho era um trabalho num restaurante. Como não falava bem português uma pessoa me levou até o trabalho. Se não deixasse esse trabalho os familiares encontrariam somente meus ossos! Eram 13 horas sem parar! (Migrante Haitiana - São Paulo/SP).

Ao longo das décadas, as mulheres quando saíam do espaço do lar para o mercado de trabalho, ocupavam os tradicionais guetos profissionais femininos, ou seja, profissões nomeadas como tipicamente femininas. Neste artigo, também ficou evidente a presença maior das mulheres nos tradicionais guetos, o que corrobora outras pesquisas (BECERRA et al, 2011; TEDESCO, 2011). Profissões onde a comunicação é um requisito importante para o trabalho, o que prejudica a inserção e a continuação das atividades por estas mulheres.

Vale ressaltar que nos depoimentos existem casos de mulheres e homens que deixaram o trabalho no Brasil porque se sentiram humilhados pelos patrões, como nos exemplos a seguir.

Foi lá no serviço quando cheguei, ele me deu uma coisa que se chama "BÛCHETTE (...) para cavar 16 buracos a 1 m50 cada um durante um dia. Todo mundo sabe que não é possível. Uma pessoa não pode furar 16 buracos a 1 m50 num dia só. E mais, a terra estava muito dura. Porém, estou cavando, cavando. Trabalhei, trabalhei. Mas quando o dia estava ao ponto de acabar, não podia mais com a minha mão. O serviço era muito pesado e não me acostumei com ele. Estou nervoso a um ponto tal que ele me encontrou chorando. Me perguntou, por que que estou chorando? Respondi: por nada. OK, passou isso. (Migrante Haitiano - Esmeraldas / MG).

A humilhação ocorreu em relação ao tipo de trabalho que realizavam e também em relação à desqualificação que recebiam dos superiores.

O dia seguinte, quando cheguei, falei para ele dizendo: você não me contratou para isso, foi como CANALIZADOR / bombeiro. Ele me falou 'não'. Você é um ajudante; Falei que eu estou aqui não era como ajudante. Ficamos discutindo. Finalmente ele diz: bom se você não quer trabalhar, sai da minha casa. Falei para ele: não tenho problema. Porque se uma pessoa fez essa casa, também eu posso fazer mil dessas. Falei e ele disse: vou deixar sua casa. Efetivamente, peguei minha maleta e sai. (Migrante Haitiano - Esmeraldas / MG).

O primeiro trabalho que encontrei deixei-o. Quando todos os brasileiros terminavam eu continuava a trabalhar. Antes de trabalhar tinha sido feito um acordo. Falaram pra mim de vir das 6 às $15 \mathrm{~h}$. Falaram pra mim que se termino de trabalhar às 17 hé hora extra. E quando vejo, chegam as 15 horas e todos os brasileiros saem e fico sozinha no restaurante. Fui eu que tive que pegar mesas para limpar, passar pano no chão, lavar os copos e xícaras de todas as pessoas que vão tomar café. Todas as coisas sobraram pra mim. E falei que já 
Inserção no Mercado de Trabalho Brasileiro por Haitianos: Uma Perspectiva

de Gênero

tinha acabado o horário. O dono respondeu: "se acabar de trabalhar agora não vou mais colocar você para trabalhar". Falei: muito obrigado, já pode encontrar outro. (Migrante Haitiana - São Paulo/SP).

Em percentual, há mais homens seguindo suas qualificações do que mulheres. Eles atuam principalmente na área de construção civil e indústria de alimentos, enquanto as mulheres têm como principal atividade os serviços gerais e, em segundo lugar, a indústria de alimentos.

Geralmente essas atividades ocupadas pelas mulheres migrantes, demandam menor força física, porém, não são serviços simples ou que exigem menor esforço. Ravenstein (1885) já ressaltava que as mulheres deslocavam não apenas para o serviço doméstico, mas a busca pelo trabalho manufatureiro também ocorria de forma expressiva.

Gráfico 4 - Setor de ocupação

Setor de ocupação preenchidos pelos haitianos entrevistados - 2013

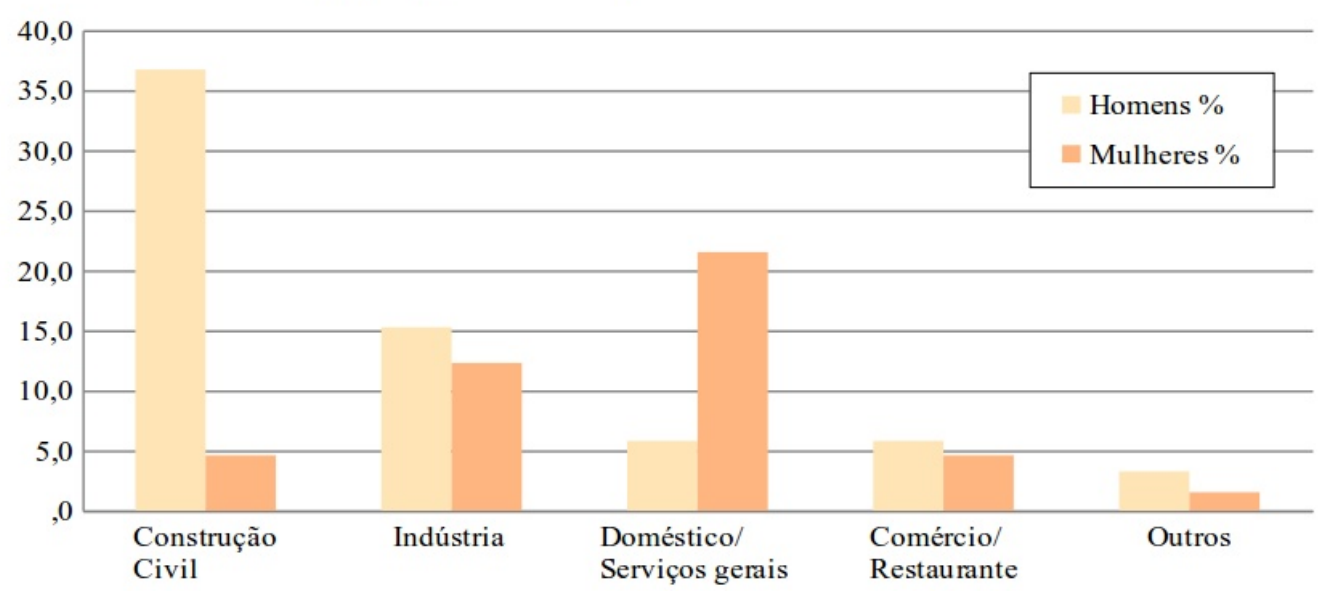

Fonte: Pesquisa OIM/CNIg (2013) - Autoria: RIBEIRO (2015

Acredita-se que, pelo homem se apresentar fisicamente mais forte que a mulher, na maioria dos casos, acaba sendo solicitado para trabalhos braçais. Já no caso da atividade na indústria, os mesmos atuam principalmente no setor alimentício, e isso pode ocorrer pelo aumento da demanda de trabalhadores em frigoríficos, principalmente na região Sul do Brasil. Trabalho que exige grande esforço físico e que não costuma ser preenchido pela população local.

Com tantos problemas, dificuldades de comunicação e entendimento de leis, o migrante haitiano se torna mais vulnerável, não tendo a opção de escolha de trabalho. A maioria tem que se submeter a serviços braçais, em péssimas condições de trabalho e em alguns casos se submete até a ocupação em condições semelhantes ao trabalho escravo, só para conseguir o que comer e onde dormir.

A situação da migrante haitiana mulher é ainda mais delicada, pois algumas delas possuem filhos e encontram grandes dificuldades de encontrar trabalho que seja flexível para levar e buscar os filhos na creche (isso, é claro, quando encontram creche), ou que pague o suficiente para que elas consigam arcar 
Inserção no Mercado de Trabalho Brasileiro por Haitianos: Uma Perspectiva de Gênero

com alimento e moradia para elas e seus filhos no Brasil, ou enviar ajuda financeira para eles no Haiti.

Saí do trabalho porque era uma escravidão: trabalhava das 8,00hs às 18,00h (dez horas de trabalho), com uns minutos para descansar; muito trabalho, muito cansaço. (Migrante Haitiana - Manaus/AM).

Eu quero trabalhar, mas eu não encontro, porque eu tenho o aluguel para paga e me alimentar, e o salário que recebo é muito pouco 700,00 reais. Tenho 3 filhos no Haiti, tenho que mandar dinheiro para eles. Tenho que mandar dinheiro para pagar as aulas. Agora está complicado. (Migrante Haitiana - Belo Horizonte/MG).

Eu passei muito trabalho por causa do meu filho, eu não consegui uma creche pra ele, até ultimamente eu achei um trabalho, mas eles não me deixam sair a tempo, eu trabalhei muito. Mas agora meu filho esta numa creche, e estou tentando me adaptar e eu quero ficar neste trabalho. Somente eles me dão bastante coisa pra fazer, por exemplo, limpando panelas, é um trabalho muito esforçado. (Migrante Haitiana - Curitiba / PR).

A informalidade no emprego é inferior à formalidade. A maioria dos migrantes haitianos, homens e mulheres, trabalha com carteira assinada.

Tabela 3 - Tipo de vínculo empregatício dos haitianos entrevistados - 2013

\begin{tabular}{|l|c|c|}
\hline & Homens \% & Mulheres \% \\
\hline Carteira Assinada & 57,8 & 33,8 \\
\hline Sem carteira assinada & 6,5 & 7,7 \\
\hline Por conta própria & 1,8 & 0 \\
\hline Não trabalha & 21,8 & 38,5 \\
\hline Não respondeu & 12,0 & 20,0 \\
\hline Total & 100,0 & 100,0 \\
\hline
\end{tabular}

Porém, ao analisar a tabela 4, acima, percebe-se que as mulheres trabalham em maior quantidade em empregos sem carteira assinada do que os homens, apesar da diferença percentual entre os sexos neste caso ser relativamente pequena.

No primeiro emprego eu era de ajudante de pedreiro na construção civil, eu não ganhava mais de um salário mínimo, minha carteira foi assinada no mesmo tempo, eu tive sorte de ajudar minha família no Haiti. (Migrante Haitiano - Porto Velho / RO).

Troquei de trabalho porque não quiseram assinar a carteira. (Migrante Haitiana - Manaus/AM).

Carolina Ribeiro, Duval Fernandes, Carolina Mota-Santos 
Inserção no Mercado de Trabalho Brasileiro por Haitianos: Uma Perspectiva

Estava esperando a carteira de trabalho, mas falaram pra mim que ia demorar quinze dias. E quando fui para pegar a carteira disseram que estava atrasada, pois cheguei às 9:30h. Não me deram a carteira. Assim quando o patrão ligou pelo telefone disse que ia pegar outra pessoa para trabalhar. Depois, outra pessoa me deu outro trabalho, mas este trabalho é como um trabalho "de companhia" em casa. Tinha gripe e conversei lá mesmo com a pessoa responsável e assim pegou outra pessoa para trabalhar no meu lugar. (Migrante Haitiana - São Paulo/SP).

No caso das mulheres haitianas, elas alegam que o fato de não saberem falar português as limita na hora de procurar por trabalho. Além disso, as relações entre patrão e colegas de trabalho se tornam muito superficiais devido à falta de comunicação. Elas também alegam que o salário não é suficiente para bancar a alimentação e a moradia e ainda enviar ajuda aos familiares. Muitas mulheres reclamam do trabalho ser muito pesado, da carga horária não ser justa em relação ao salário.

Você faz 10 horas de trabalho, eles não pagam você bem. Temos uma casa para pagar, 500,00 reais por mês depois pagar luz, água, comida, não dá para sobreviver, você recebe 500,00 reais para pagar a casa, a luz, a água, a saúde. Os patrões não querem ajudar os Haitianos. (Migrante Haitiana - Belo Horizonte/MG).

Poderíamos ter um relacionamento ${ }^{3}$ de verdade, mas não falamos a língua, falamos por gestos, para nos entendermos. Ou então, se uma Haitiana fala português, pode nos chamar. Por isso é que eles dizem que você é incapaz de ter um bom relacionamento com eles. (Migrante Haitiana- Belo Horizonte/MG).

Mesmo pegando um Haitiano para traduzir, eles exploram para trabalhar para eles. Eles já me exploram, quando chega a hora de receber, não pagam. Eu fico com raiva. (Migrante Haitiana - Belo Horizonte/MG).

\section{Considerações Finais}

O objetivo deste artigo foi analisar, a partir de uma perspectiva de gênero, como se deu o processo de inserção de haitianos no mercado de trabalho brasileiro, que migraram para o Brasil após o terremoto de 2010.

Como foi verificado na literatura, atualmente o fenômeno migratório é mais complexo (RIBEIRO, 2005), entretanto, a mulher continua a ser invisível nesse processo ou agrupada nas mesmas dimensões que os homens (TEDESCO, 2011).

Em relação aos 340 imigrantes haitianos que chegaram ao Brasil, os dados revelaram que tanto os homens quanto as mulheres tiveram como principal motivo de terem deixado o Haiti a busca por trabalho. Além disso, ambos

2 A respeito de relacionamento com os patrões. 
passaram por situações e constrangimentos na busca por emprego no Brasil, pois há uma série de informações que não chegam ao conhecimento deles antes de migrar.

Este estudo traz particularidades no processo de migrar quando se compara homens e mulheres. $\mathrm{O}$ desrespeito no tratamento entre patrão e empregado ou até mesmo entre colegas de trabalho são queixas relatadas pelos imigrantes haitianos homens. Já com as mulheres a situação é diferente. Por terem muita dificuldade de se comunicarem devido à língua, elas são dispensadas de seus trabalhos. Os trabalhos femininos, quando braçais (faxineira. babá, garçonete), exigem um mínimo de comunicação com algum brasileiro. Vale lembrar que faz parte da cultura haitiana a submissão da mulher em relação ao homem, e a imigrante haitiana se vendo em situação de vulnerabilidade, sem domínio da língua e sem emprego, pode se unir a um homem como forma de proteção.

A maioria dos homens se submete a serviços braçais em péssimas condições de trabalho, e a situação das mulheres é ainda mais delicada, uma vez que enfrenta grandes dificuldades de encontrar trabalho que seja flexível para levar e buscar os filhos na creche.

Espera-se, através desse manuscrito, contribuir com os estudos de imigração, principalmente relacionados a uma perspectiva de gênero, desconstruindo a visão da mulher como coadjuvante nesse processo e entender, de forma mais aprofundada, a participação de ambos nesse processo. Além disso, espera-se que esse estudo contribua para a criação de políticas que auxiliem no processo de entrada e adaptação no país.

\section{Referências}

ARAÚJO, Maria de Fátima. Diferença e igualdade nas relações de gênero: revisitando o debate. Psicologia Clinica, v. 17, n. 2, p. 41 - 52, 2005.

BECERRA, Patricia Vargas; CANALES, Alejandro; ARMAS, Israel Montiel. Migración, género y salud sexual y reproductiva: la vulnerabilidad de los migrantes haitianos em la República Dominicana. In: PIZARRO, Jorge Martínez. Población y derechos humanos en América Latina - ALAP. Rio de Janeiro: Asociación Latinoamericana de Población, 2011, p. 167 - 194.

BENTOLILA, Alain, GANI, Léon. Langues et problèmes d'éducation en Haïti. Langages, v. 15, n. 61, p. 117 - 127, 1981.

BORJAS, George. Economic theory and international migration. International Migretion Review, v. 23, n. 3, p. 457 - 485, 1989.

BOURDIEU, Pierre. La dominación masculina. Anagrama, Espanha: 2000.

CAISSE, Peter Thomas. A Vitalidade Linguística dos Crioulos do Haiti e da Luisiana: Os Limites da Política e das Atitudes Linguísticas. 2012. Dissertação (Mestrado em Lingúistica) - Universidade de Campinas, Campinas. 
Inserção no Mercado de Trabalho Brasileiro por Haitianos: Uma Perspectiva

de Gênero

CAPPELlE, Mônica Carvalho Alves; BRITO, Mozar José; MELO, Marlene Catarina de Oliveira Lopes; VASCONCELOS, Kamila Anderson. A produção científica sobre gênero nas organizações: uma meta-análise. REAd, v. 13, n.3, p. $501-528,2007$.

CESAR, Tamires Regina Aguiar de Oliveira; PINTO, Vagner Andre Morais. A produção intelectual da geografia brasileira, entorno das temáticas de gênero e sexualidades: uma visão a partir dos periódicos on-line. Revista Latinoamericana de Geografia e Gênero, v. 6, n. 2, p. 119 - 132, 2015.

COSTA, Felizardo Tchiengo Bartolomeu; JUSTO, José Sterza. Imigração e relações de gênero: subjetividades emergentes ou em recomposição? Revista Latino-americana de Geografia e Gênero, v. 7, n. 2, p. 34 - 53, 2016.

CREESE, Gillian; WIEBE, Brandy. Survival employment: gender and deskilling among African Immigrants in Canada. International Migration, v. 50, n. 5 , p. $56-76,2009$.

LEE, Everett S. Uma teoria sobre migração. In: MOURA, Hélio Augusto de; MOURA, Hélio Augusto de (Coord.). Migração interna: textos selecionados. Fortaleza: BNB, ETENE, 1966, p. 89-114.

FERNANDES, Duval; MILESI, Rosita; PIMENTA, Bruna; do CARMO, Vanessa. Migração dos haitianos para o Brasil a RN no 97/2012: uma avaliação preliminar. Cadernos de Debates Refúgio, Migrações e Cidadania, v. 8, n. 8, p. $55-71,2013$.

ITZIGSOHN, José; GIORGULI-SAUCEDO, Silvia. Incorporation, transnationalism, and gender: immigrant incorporation and transnational participation as gendered processes. IMR, v. 39, n. 4, p. 895 - 92, 2005.

LEWIS, Arthur. El desarrollo econômico com oferta ilimitada de trabajo. In: AGARWALA A. N.; SINGH, S. La economia del subdesarrollo. Madrid: Editorial Tecnos, 1963, p. 333 - 374.

LIU, Mao. Mei. Migrant Networks and International Migration: Testing Weak Ties. Departament de Ciències Polítiques i Socials. Universitat Pompeu Fabra. Barcelona, Spain. October, 2011.

LOURO, Guacira Lopes. Gênero, sexualidade e educação: uma perspectiva pós-estruturalista. Petrópolis, RJ: Vozes, 2013.

MENJÍVAR, Cecília; SALCIDO, Olivia. Immigrant women and domestic violence: common experiences in diferente countries. Gender \& Society, v. 16, n. 6, p. $898-920,2002$.

NUNAN, Carolina dos Santos. De volta para casa: a re-inserção do migrante internacional retornado no mercado formal de trabalho. 2006. 
Inserção no Mercado de Trabalho Brasileiro por Haitianos: Uma Perspectiva

de Gênero

Dissertação (Mestrado em Tratamento da Informação Espacial) - Pontifícia Universidade Católica de Minas Gerais, Belo Horizonte.

PERES, Roberta Guimarães. Mulheres na fronteira: a migração de bolivianas para Corumbá - MS. Revista Territórios \& Fronteiras, v. 8, n. 2, p. 120 $137,2015$.

PERES, Roberta. Imigração e Gênero: as mulheres haitianas no Brasil. In: BAENINGER, Rosana; PERES, Roberta; FERNANDES, Duval; SILVA, Sidney; ASSIS, Gláucia; CASTRO, Maria da Consolação; COTINGUIBA, Marília (orgs). Imigração haitiana no Brasil. Jundaí: Paco Editorial, 2016, p. $253-266$.

PIORE, Michael. Birds of passage: Migrant labor in industrial societies. Cambridge: Cambridge University Press, 1979.

RAVENSTEIN, Ernest. As Leis da Migração. In MOURA, Hélio Augusto de; MOURA, Hélio Augusto de (Coord.). Migração interna: textos selecionados. Fortaleza: BNB, ETENE, 1885, p.19-88.

RIBEIRO, Carolina. Migração haitiana para o Brasil: processo de fixação e adaptação: uma questão de gênero (2013-2014). Dissertação (Mestrado em Tratamento da Informação Espacial) - Pontifícia Universidade Católica de Minas Gerais, Belo Horizonte.

SILVA, Telma Ferreira; CASTRO, Sheila; MENESES, Elisângela Ferreira; SILVA, Maria das Graças Silva Nascimento; SILVA, Josué da Costa. Qual espaço para discutir gênero? Revista Latino-americana de Geografia e Gênero, v. 6, n. 1, p. 169 - 183, 2015.

SILVA, Joseli Maria. Fazendo geografias: pluriversalidades sobre gênero e sexualidades. In: SILVA, Joseli Maria (Org.). Geografias subversivas: discursos sobre espaço, gênero e sexualidades. Ponta Grossa: Todapalavra, 2009 , p. $25-53$.

SUÁREZ-OROZCO, Carola; QIN, Desirée Baolian. Gendered perspectives in psychology: immigrant origin youth. IMR, v. 40, n. 1, 2006, p. 165 - 198.

TEDESCO, João Carlos. O gênero na imigração: redefinições de papéis e dinâmicas étnicas. Revista Latino-americana de Geografia e Gênero, v. 2, n. 1, p. $44-55,2011$.

ZENTGRAF, Kristine. Immigration and women's empowerment: Salvadorans in Los Angeles. Gender \& Society, v. 16, n. 5, p. 625 - 646, 2002.

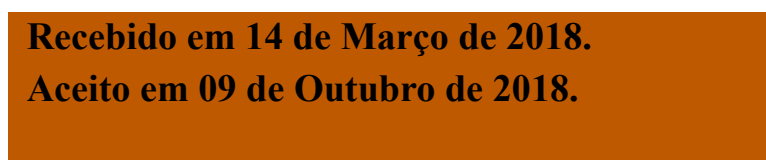

Carolina Ribeiro, Duval Fernandes, Carolina Mota-Santos 